\title{
Writing to patients
}

\author{
Marios Pierides
}

In the past decade easily accessible information on a range of mental health issues has become widely available. 'Patients' are no longer in passive receipt of prescribed care or information by omnipotent doctors. Psychiatric patients in particular aspire to be equal partners in negotiating their treatment.

The Royal College of Psychiatrists' Public Education Committee, in consultation with the College's Patients and Carers Liaison Group and the Zito Trust, has recently circulated a checklist of questions that patients can ask their psychiatrists. These questions are addressed in any thorough consultation, but traditionally no written feedback is given because a dictated outpatient clinic letter is sent to the general practitioner.

\section{The current status}

There have been no published data on the effects of writing to psychiatric patients. Gastroenterologists (Eaden et al, 1998) have found that $75 \%$ of patients wished to receive written communications from their hospital specialist, $90 \%$ wanted to know more about their diagnosis and 92\% requested more information about their medication. In general practice, appropriate letter writing was found to greatly improve doctorpatient communication, and avoided leaving the patient feeling "apathetic, baffled or scared to death" (Albert, 1991).

In cognitive analytical therapy (CAT) (Ryle, 1982), writing to patients is routine. Cognitive analytical therapy is an integrated form of brief structured psychotherapy, which incorporates psychoanalytical, cognitive and behavioural ideas into a 'common language' for the psychotherapies. The essential steps in CAT evaluation include standard assessment procedures and reformulating the patient's problems through encouragement and active participation and collaboration. Following the initial formulation, a written letter from the therapist is sent to, discussed and shared with the patient. The letter links the patient's presenting problems, history and problematic patterns with the CAT formulation. 'Homework' guidelines are contained in the initial letter to emphasise the target problems and areas of work ahead. A 'goodbye' or discharge letter is provided at the end of therapy, which evaluates the patient's achievements and promotes further self-management.

Written self-help initiatives, such as the use of crisis cards, are becoming increasingly common (Sutherby \& Szmukler, 1998). In one form, the crisis card developed by Survivors Speak Out allows patients to nominate a friend or relative to be contacted in times of crisis and provides space for patients to supply any information they wish and to request specific actions to be carried out. The Camberwell Joint Crisis Plan card will contain the patient's current care plan and action plans in a crisis or emergency.

During the treatment of patients with eating disorders (Schmidt \& Treasure, 1993), therapists write to their patients to outline the problems. Patients with eating disorders are encouraged to write their own letters, either to their doctor or to a friend, in order to assist clarification of the issues around their needs and care plans.

\section{Local initiatives}

In our local psychiatric service, internal audits revealed a high rate of out-patient clinic nonattendance for new and follow-up patients. In an attempt to address the non-attendance, the author writes to patients after an out-patient appointment and addresses the issues raised in consultation. The letters thank the patient for attending and, if appropriate, the agreed diagnosis, care plan and prognosis will be discussed. Jargon-free explanations around medication and side-effects will be addressed. The letter will remind the patient of the date, time and venue of their next appointment. The letter replaces the traditional letter to the general practitioner, although a copy of the letter to the patient is sent to the general practitioner. Repeat audits have shown a decline in non-attendance. Of particular encouragement has been the large number of written responses from patients. General practitioners, social workers and other agencies have welcomed this initiative. There has been a reduction in the number of complaints received by the out-patient clinic.

Informed consent to treatment is a statutory requirement under the Mental Health Act 1983. Following a face to face discussion with the patient about medication and consent to treatment, a letter is sent to the patient noting the 
discussion, with particular emphasis on the patient's right to refuse treatment and seek a second opinion. The side-effects of the particular treatments and a note on the consequences of stopping medication are included, if appropriate.

Other initiatives currently being explored include replacing the traditional tribunal report with a personal letter to the patient, copied to the tribunal president and to others involved in the application, such as the patient's solicitor and social worker.

\section{Comments}

In her paper published in this issue (Gauthier. 1999). Dr Gauthier makes the important point that because medical records can be subpoenaed for civil or criminal proceedings and because psychiatric reports are routinely made available to all parties in Court proceedings, the fear of exposing oneself to litigation by writing to patients is not justified.

Issues around confidentiality need to be addressed before any written information is sent to the patient, because patients might be living with people who have access to their mail. The words 'Strictly Private and Confidential' or
'Addressee Only' help to protect patient confidentiality.

The reluctant collaborator (who refuses appointments, home visits or access to carers and declines medication) is better able to make a decision about future treatment when provided with written information regarding the consequences of disengagement for their prognosis.

Colleagues who feel persuaded to begin writing to their patients are reminded that the College 'Check-list of questions for their psychiatrists from their patients' provides helpful guidelines.

\section{References}

ALBERT. T. (1991) Undervalued skill of letter writing in general practice. Pulse, 28, 30-31.

EADEN, J. A., WARD, B., Smrth, H., et al (1998) Are we telling patients enough? A pilot study to assess patient information needs in a gastroenterology outpatient department. European Journal of Gastroenterology. 10, 63-67.

GAUTHIER, J. (1999) Writing to famillies. Psychiatric Bulletin. 23. 387-389.

RYLE, A. (1982) Psychotherapy. A Cognitue Integration of Theory and Practice. London: Academic Press.

SCHMIDT, U. \& TREASURE. J. (1993) Getting Better But(e) by Bit(e). UK: Lawrence Erlbaum Associates.

SUTHERBY, K. \& SZMUKLER, G. (1998) Crisis cards and selfhelp crisis initiattves. Psychiatric Bulletin. 22, 4-7.

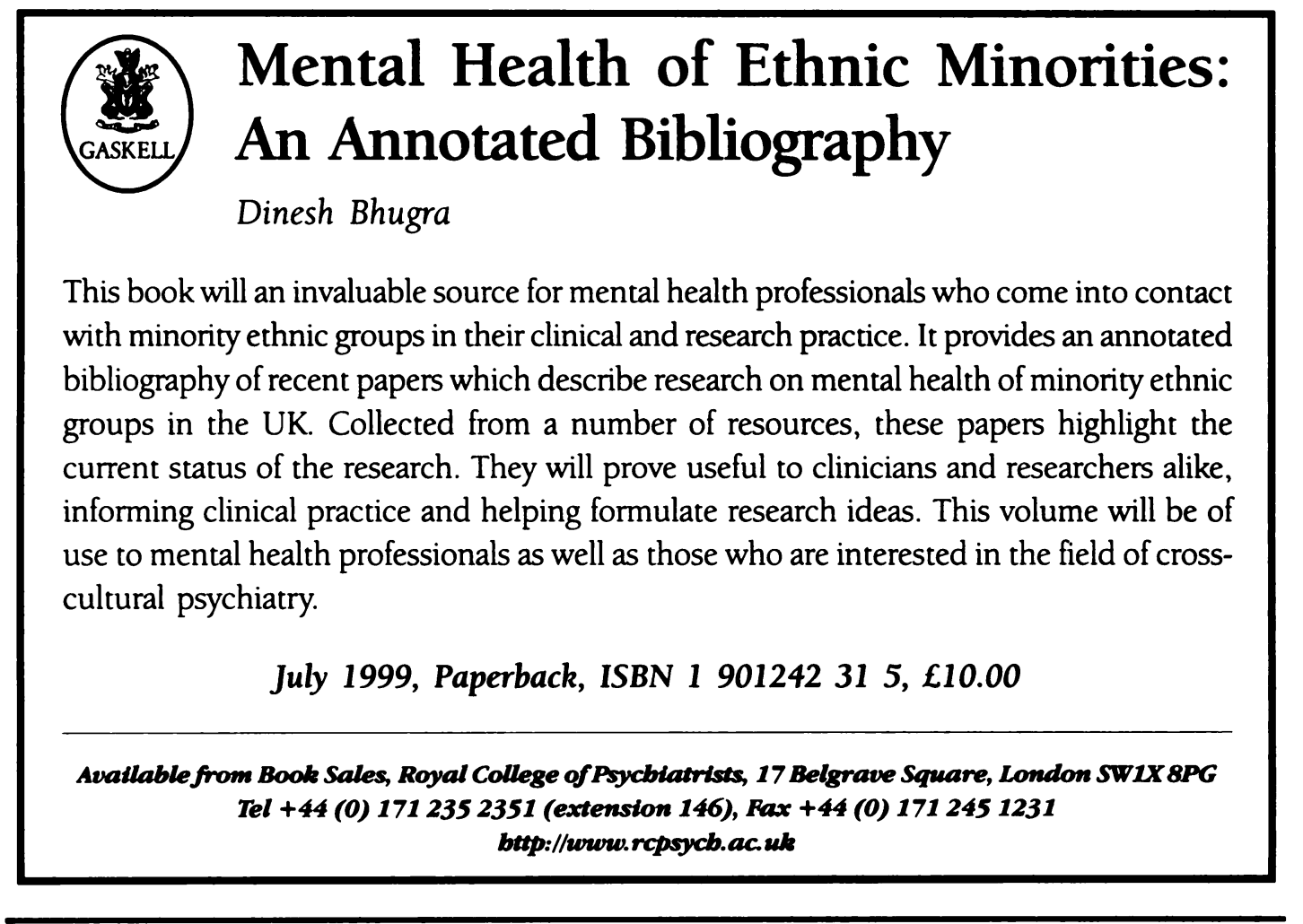

